\title{
Viaje dinámico por temas de la cátedra de Lingüística General*
}

JOSELYN CORREDOR TAPIAS ${ }^{* *}$ joselyn1973@yahoo.es

Recepción: 24 de octubre de 2014

Aprobación: 2 de junio de 2015

Forma de citar este artículo: Corredor Tapias, J. (2016). Viaje dinámico por temas de la cátedra de Linguística General. Cuadernos de Lingüística Hispánica, (27), 179-207.

* Artículo de investigación científica que recoge resultados del proyecto intitulado "Viaje dinámico por ciertos temas básicos de la cátedra de Lingüística general: Hacia la construcción y aplicación de actividades pedagógicas".

** Magíster en Linguística Hispánica, Investigación y Docencia, y Licenciado en Ciencias de la Educación: Español - Francés de la Universidad Pedagógica y Tecnológica de Colombia, Colombia. Docente de la Escuela de Idiomas y coordinador académico de la Maestría en Lingüística de esta misma institución. Integrante del grupo de investigación Episteme. 


\section{Resumen}

Este artículo tiene como objetivo dar a conocer aspectos relacionados con la experiencia investigativa del autor, al plantear y aplicar once actividades pedagógicas que faciliten un acercamiento y apropiación adecuados de temas abordados en la cátedra de Linguística general, por parte de un grupo de estudiantes de la Licenciatura en Lenguas Extranjeras de la Universidad Pedagógica y Tecnológica de Colombia (UPTC). El marco pedagógico se basó en postulados del aprendizaje significativo y la metodología se enmarcó en la investigación aplicada y dentro del diseño investigativo del enfoque cualitativo denominado: Investigación-acción. Se recurrió a la observación, a conversaciones espontáneas y al diario de campo como instrumentos de recolección de información. Con las actividades se propició que, en los educandos, se diera una actitud dinámica para apropiarse de temas y postulados básicos de la lingüística. En primer lugar, se hace referencia al constructo teórico; enseguida, al marco pedagógico, y, después, a la metodología; luego, se plantea, grosso modo, las once actividades realizadas; ulteriormente, se dan a conocer unos resultados y se remata el texto con conclusiones.

Palabras clave: lingüística general - cátedra - actividades - aprendizaje significativoexperiencia pedagógica.

\section{A dynamic journey through the teaching of the General Linguistics class.}

\section{Abstract}

The objective of this article is to highlight some of the aspects related to the research experience of the author when formulating and applying eleven pedagogical activities designed to guide students in the approach and appropriation of the topics adressed in the General Linguistics class, by a group of students of the Foreign Language Teaching degree from the Universidad Pedagógica y Tecnológica de Colombia (UPTC). The pedagogical framework is based on meaningful learning approaches and the methodology is framed in applied research, in the cualitative standpoint known as action research. The data-collection instruments used in this research were direct observation, spontaneous dialogue and the field diary. The pedagogical activities developed fostered a dynamic attitude in the students, with the purpose of acquiring the basic topics and approaches to Linguistics. First of all, the article makes reference to the theoretical constructs; then, to the pedagogical framework, and then, to the methodology; after that the eleven pedagogical activities developed in class are presented; subsequently, some of the results of the research are presented, and at the end, conclusions are given. 
Key words: General Linguistics, teaching, activities, meaningful learning, pedagogical experience.

\section{Voyage dynamique pour les sujets du cours de Linguistique Générale}

\section{Résumé}

Cet article a l'objectif de faire connaitre des aspects concernant l'expérience en recherche de l'auteur, en présentant et en appliquant onze activités pédagogiques qui facilitent une approche et une appropriation adéquates de sujets abordés dans le cours de Linguistique générale, de la part d'un groupe d'étudiants de la Licence en Langues Étrangères de l'Universidad Pedagógica y Tecnológica de Colombia (UPTC). Le cadre pédagogique s'est basé sur des postulats de l'apprentissage significatif, et la méthodologie s'est encadrée dans la recherche appliquée et dans le dessin en recherche de l'approche qualitative appelée : Recherche-action. On a fait recours à l'observation, aux conversations spontanées et au carnet de route, en tant qu'instruments de collecte d'information. Avec les activités on a rendu propice que, chez les apprenants, soit donné une attitude dynamique pour s'approprier de sujets et de postulats de base de la linguistique. En premier lieu, on fait référence à la construction théorique ; ensuite, au cadre pédagogique, et après, à la méthodologie. Ensuite, on pose la question, grosso modo, concernant les onze activités réalisées ; ultérieurement, on fait connaitre quelques résultats et on met fin au texte avec des conclusions.

Mots clés: linguistique générale - cours - activités - apprentissage signigicatif expérience pédagogique.

\section{Viagem dinâmica por temas da cátedra de Linguística Geral}

\section{Resumo}

Este artigo tem como objetivo dar a conhecer aspectos relacionados com a experiência de pesquisa do autor, ao plantear e aplicar onze atividades pedagógicas que facilitem uma aproximação e uma apropriação adequadas de temas abordados na cátedra de Linguística geral, por parte de um grupo de estudantes da Licenciatura em Línguas Estrangeiras da Universidad Pedagógica y Tecnológica de Colombia (UPTC). 0 marco pedagógico se baseou em postulados da aprendizagem significativa e a metodologia se enquadrou na pesquisa aplicada e dentro do desenho de pesquisa do enfoque qualitativo 
denominado: Pesquisa-ação. Foram utilizadas a observação, as conversações espontâneas e o diário de campo como instrumentos de coleta de informação. Com as atividades se propiciou que, nos educandos, se tenha dado uma atitude dinâmica para apropriar-se de temas e postulados básicos da linguística. Em primeiro lugar, faz-se referência ao constructo teórico; em seguida, ao marco pedagógico, e, depois, à metodologia; após, se planteia, grosso modo, as onze atividades realizadas; ulteriormente, se dão a conhecer uns resultados e se remata o texto com conclusões.

Palavras chave: linguística geral - cátedra - atividades - aprendizagem significativaexperiência pedagógica. 
"El desarrollo de la lingüística, la ciencia del lenguaje, ha cobrado auge especial en las últimas décadas. El interés popular por el papel del lenguaje en relación con las creencias y la conducta bumana ha aumentado y se ha desarrollado de modo concomitante la conciencia de la necesidad de una disciplina académica independiente que aborde de modo adecuado la diversidad y la complejidad de los fenómenos lingüísticos" (Crystal, 1994, p. 412).

\section{Introducción}

El presente artículo da a conocer aspectos relacionados con el trabajo investigativo intitulado "Viaje dinámico por ciertos temas básicos de la cátedra de Linguística general: Hacia la construcción y aplicación de actividades pedagógicas", realizado en el segundo semestre de 2013 y en el primero de 2014. Con este trabajo, se buscó plantear y aplicar una propuesta de once actividades pedagógicas que facilitaran un acercamiento y una apropiación adecuados de unos temas abordados en la cátedra de Lingüística general por parte de un grupo de estudiantes de la Licenciatura en Lenguas Extranjeras, Programa adscrito a la Escuela de Idiomas de la UPTC.

El artículo, inicialmente, expone el marco teórico el cual presenta un acercamiento a la concepción de la linguística desde épocas remotas hasta perspectivas actuales y la definición de la cátedra de Lingǘstica general; posteriormente, se explicita el marco pedagógico que sustenta las actividades; en dicho marco, se tiene en cuenta postulados del aprendizaje significativo y se plantean tres categorías de análisis de lo ocurrido en su puesta en acción en el aula; a continuación, aparece la metodología, aquí se presenta la población; el tipo de investigación -investigación aplicada- y el diseño investigativo investigación acción-; luego, se propone un cuadro con una síntesis de las actividades; después, se hace referencia general a los resultados obtenidos; seguidamente, se exponen unas conclusiones; finalmente, se presentan las referencias bibliográficas.

\section{A manera de marco teórico}

En este proceso investigativo se tuvo en cuenta un constructo teórico que se constituyó en referente para la propuesta de actividades pedagógicas; estos elementos teóricos giran sobre dos aspectos: un acercamiento a la Lingüística y definición de la cátedra de Lingüística general. 


\subsection{Lingüística}

El estudio del lenguaje ha sido un tema de interés y de curiosidad para el hombre desde tiempos remotos; en las primeras etapas, este estudio estuvo muy influenciado por lo divino; el lenguaje se consideraba un regalo de la divinidad (Véase, Cisneros y Silva, 2010); además de este enfoque, el estudio del lenguaje -por ejemplo en la cultura griegaestuvo relacionado con la lógica y la filosofía; precisamente, el lenguaje se consideraba parte de sus hermanas mayores: la lógica y la filosofía (Véase, Bernal Leongómez, 1982). De acuerdo con estas visiones, el estudio del lenguaje se llevó a cabo desde interesantes ópticas, pero ninguna de ellas contenía el componente científico. Este aparece gracias al ginebrino Ferdinand de Saussure, considerado padre de la lingüística moderna quien en su obra Curso de Lingüística general (redactado, fundamentalmente, por dos de sus discípulos, Charles Bally y Albert Sechehaye, y publicado en 1916) sienta las bases del estudio científico del lenguaje (Véase, De Saussure, 1974).

Esta ciencia evolucionó, paulatinamente, en el siglo XX, desde el estructuralismo, pasando por la teoría de lingüística generativo-transformacional (Noam Chomsky) hasta arribar a la textolingüística, y al análisis del discurso (Teun Adrián Van Dijk) y a la elucidación de las relaciones múltiples que se desprenden de la reflexión en torno de la lengua como asidero de las actividades vitales del hombre, y a la consideración de la dimensión pragmática, comunicativa, social y psicológica del hablante. Es de anotar que el campo de la linguística, hoy, abarca estudios interdisciplinarios y dirige su atención hacia una perspectiva discursiva. El discurso, el contexto, el texto, y la intención comunicativa, son ejes sobre los cuales se soporta el andamiaje de los estudios lingüísticos.

Complementario a esto, para algunos estudiosos, actualmente, la lingüística no se limita al estudio de la lengua -como se consideró tradicionalmente-; por el contrario, debe ocuparse del estudio del lenguaje (facultad lingüística). Por tanto, se puede concebir como "una ciencia cognitiva dedicada al estudio de los procesos de significar en la doble dimensión de producción y recepción" (Tobón de Castro, 2007, p. 27).

De acuerdo con lo anterior, la lingüística se puede considerar en términos generales, como:

La ciencia del lenguaje. En este sentido, el término lenguaje comprende la facultad comunicativa propia de los humanos y las lenguas naturales en las que este se manifiesta, junto con sus elementos constitutivos, las relaciones de estos, y las leyes o reglas de su funcionamiento. La "Lingüística" tendría, pues, como objeto esa facultad y sus manifestaciones; habría de describir y explicar sus formas y funciones 
como expresión del pensamiento humano y de la comunicación social (Alcaraz Varó y Martínez Linares, 2004, p. 383).

En esta ciencia se ha establecido, según algunos autores, la distinción entre lingüística teórica y lingüística aplicada. La primera se centra "en el estudio del sistema lingüístico" (Castro et al., 1999, p. 131); la segunda, en la aplicación de los saberes que tenemos sobre las lenguas a la solución de problemas. La lingüística aplicada se puede abordar desde varias perspectivas que se pueden categorizar en dos grupos: 1. El teórico y 2. El práctico. El primer grupo tiene que ver con el campo interdisciplinario; aquí se pueden citar, verbi gracia: la psicolinguística, la pragmalingüística y la etnolingüística. Estas abordan el estudio de "la actuación lingüística, del uso de la lengua en situación comunicativa real" (p. 132). El segundo grupo estudia la manera como se pueden emplear saberes de la lingüística teórica y de la lingüística aplicada teórica en distintos "campos concretos de la vida cotidiana" (p. 132); entre estos se encuentra, por ejemplo, la enseñanza de la lengua materna.

En la formación de docentes de lengua española, es imprescindible abordar la lingüística, puesto que esta es componente fundamental para que el futuro docente lleve a cabo una labor pertinente y eficaz para lo cual debe "conocer los presupuestos básicos de la lingüística, los diversos acercamientos de esta disciplina al fenómeno lingüístico [...] [esto] le permitirá [...] tener los elementos de juicio necesarios para determinar qué modelo [lingüístico] orientará su labor en el aula de clase, o qué elementos de toda esa teoría lingüística son susceptibles de trabajarse en clase" (p. 135).

\subsection{Cátedra de Lingüística general}

Asignatura que cursan los estudiantes del primer semestre del Programa de Licenciatura en Lenguas Extranjeras, Programa adscrito a la Escuela de Idiomas de la Uptc. Esta cátedra es un curso de iniciación a la lingüística. En esta, se lleva a cabo un acercamiento general a los conceptos básicos de la lingüística. Así mismo, se realiza un intento de aproximación a las principales perspectivas, concepciones y movimientos del estudio científico del lenguaje.

En la cátedra se abordan algunos contenidos temáticos, entre los que se pueden citar: actitud prescriptiva, descriptiva y explicativa frente a los hechos de la lengua y del lenguaje; unos conceptos operativos: Lenguaje, lengua, habla, dialecto, idiolecto, lingüística, etc.; acercamiento a una breve historia general de la lingüística; disciplinas y campos de la lingüística; algunos lingüistas importantes: vida y obra; sobre las lenguas del mundo: propuesta de clasificación; Ferdinand de Saussure y el estructuralismo: 
consideraciones y principios básicos; aproximación a Noam Chomsky y a la lingüística generativo-transformacional; finalmente, un vistazo a la Lingüística textual y al discursismo.

\section{Del marco pedagógico}

En el Marco pedagógico, se recurrió a ciertos postulados del aprendizaje significativo (Ausubel, 1968; Barriga Arceo, Díaz y Hernández Rojas, 1999; Martínez de Correa, 2007). En uno de tales postulados, se considera que una nueva información se articula de forma no arbitraria y sustantiva con la información que el estudiante ya posee. La nueva información se relaciona con

conocimientos específicamente relevantes [(subsumidores)] [...]. Nuevas ideas, conceptos, proposiciones pueden aprenderse significativamente (y retenerse) en la medida en que otras ideas, conceptos, proposiciones, específicamente relevantes e inclusivos estén adecuadamente claros y disponibles en la estructura cognitiva del sujeto y funcionen como puntos de "anclaje" a los primeros (Moreira et al., 1997, p. 2).

A más de esto, el conocimiento que el alumno "incorpora a la estructura cognitiva es la sustancia [el concepto, la idea] del nuevo conocimiento, no las palabras precisas usadas para expresarlas" (Moreira et al., 1997, p. 2). Es decir, un "mismo concepto o proposición puede expresarse de manera sinónima y seguir transmitiendo exactamente el mismo significado" (Barriga Arceo y Hernández Rojas, 1999, p. 22). La interrelación entre la información nueva y la estructura cognitiva existente en el alumno, genera una reorganización de dichas informaciones para crear, así, un nuevo conocimiento, que le sea útil para aplicarlo.

Este aprendizaje -siguiendo a Bara Soro (2001, pp. 48-50)- es un proceso: a) cognitivo, el discente maneja y construye conocimiento; se aprende, pensando; b) mediado, la articulación que establece el estudiante entre la nueva información y su estructura cognitiva, está mediada por factores sociales - "En el ámbito de la Institución educativa, esos [factores] son, de manera sobresaliente, el docente y los compañeros de aula" (Barriga Arceo y Hernández Rojas, 1999, p. 1) -; c) activo, requiere de la participación del estudiante; esta se orienta hacia un propósito; d) estratégico, los estudiantes utilizan estrategias como organizar, elaborar, repetir, redactar, sustentar, etc. A más de esto, el aprendizaje significativo se obtiene, principalmente, por medio del lenguaje verbal.

Aspecto importante en este tipo de aprendizaje es "según Ausubel, [cómo] la estructura cognitiva tiende a organizarse jerárquicamente en términos de nivel de abstracción, generalidad e inclusividad de sus contenidos" (Moreira, 1997, p. 3). Es 
así como se pueden dar varias formas de aprendizaje; por ejemplo: 1) el aprendizaje subordinado (asimilación derivativa y asimilación correlativa). La asimilación derivativa tiene lugar cuando "se incorpora la nueva información como un ejemplo, como una derivación de la información que ya posee el sujeto" (Bara Soro, 2001, p. 47); la correlativa, cuando "se vincula la nueva información como una extensión o modificación de los conocimientos poseídos ya por el estudiante" (p. 47). 2) El aprendizaje supraordinado, cuando "se vincula la nueva información como una idea o concepto que abarca y engloba las ideas previas que ya posee el sujeto" (p. 47); y 3) el aprendizaje combinatorio, cuando "la nueva información se relaciona con las ideas que previamente posee el estudiante, sin una vinculación de modo subordinado ni supraordinado" (p. 48); en esta forma de aprendizaje, "puede integrarse un conocimiento nuevo a otro ya existente, por analogía." (Sanjurjo y Vera, 1994, p. 30). Un ejemplo sería, según Ausubel (1963), "la relación precio/demanda" (Moreira, 1997, p. 4).

Para facilitar el aprendizaje significativo: 1) Es necesario que el contenido por aprender tenga una estructura lógica y una organización coherente para que el alumno pueda relacionarlo, de la mejor manera, con lo que sabe. Por esto, es preciso realizar "un análisis previo de aquello que se va a enseñar" (p. 18), y 2) Se debe tener presente la estructura cognoscitiva o conocimientos previos del aprendiz. Es importante "la disponibilidad de subsumidores en la estructura cognitiva" (p. 18). Cuando tales subsumidores no existen o están obliterados [olvidados o borrados], Ausubel (1968, p. 148) plantea la estrategia de los organizadores previos: materiales introductorios dados antes del material de aprendizaje. Estos sirven de anclaje momentáneo entre lo que el aprendiz ya sabe y lo que debe saber, con el fin de que el nuevo material se aprenda de manera significativa.

En la programación del contenido de la disciplina, se debe tener en cuenta cuatro principios (Ausubel, 1968, p. 152): 1) La diferenciación progresiva: las ideas más generales e inclusivas del contenido se dan al inicio de la instrucción y, progresivamente, deben distinguirse en términos de detalle y especificidad; 2) La reconciliación integrativa: "la instrucción debe explorar relaciones entre ideas, apuntar similitudes y diferencias importantes y reconciliar discrepancias reales o aparentes". (Moreira, 1997, p. 19); 3) La organización secuencial, el docente presenta los temas de manera coherente y secuenciada (teniendo presente lo relacionado con los principios anteriores); y 4) La consolidación: antes de presentar nuevos contenidos, es necesario que los temas precedentes hayan sido aprendidos por el alumno, de manera clara y organizada; además, es pertinente "la reiteración y la realización de tareas en contextos y momentos diferentes para que 
se produzca la generalización y la interiorización efectiva y significativa de lo aprendido" (Rodríguez Palmero, 2010, p. 18).

En el aprendizaje significativo, el alumno desempeña una función dinámica y participativa: él recibe un contenido dado por el docente (recepción); relaciona esta información (información nueva) con su estructura cognitiva (asimilación cognitiva), la procesa activamente; la asimila y la retiene. Descubre un nuevo conocimiento, crea y construye nuevas ideas (descubrimiento /producción). Es así como, el estudiante debe: "diferenciar y organizar los conceptos y las proposiciones [;] incorporar a su estructura cognoscitiva los conceptos [...] enseñados [...]; comprobar que su estructura ha sido impactada $[. .$.$] , al participar activamente en clase 0$ mediante trabajos presentados con lenguaje propio" (Martínez de Correa, 2007, pp. 150; 161).

En esta perspectiva pedagógica, el maestro es un facilitador, "organizador y mediador en el encuentro del alumno con el conocimiento [...] la meta de la actividad docente es incrementar la competencia, la comprensión y la actuación autónoma de sus alumnos" (Barriga Arceo y Hernández Rojas, 1999, p. 1). Para esto, el maestro: selecciona y utiliza los conceptos, las proposiciones y contenidos temáticos por enseñar; procura "desencadenar" el interés del alumno por aprender; intenta establecer conocimientos previos del estudiante -para lo cual puede recurrir a estrategias, como: lluvia de ideas; formulación de interrogantes insertados en la situación de enseñanza o en un texto; elaboración y aplicación de cuestionarios y ejercicios, para que sean resueltos por los alumnos; diseño y aplicación de situaciones donde el estudiante dé a conocer su opinión sobre un tema determinado-; facilita la relación de información nueva con saberes previos, recurriendo, por ejemplo, a situaciones, experiencias y actividades en donde el alumno pueda participar de forma motivante y divertida. Así mismo, puede recurrir a: organizadores previos, analogías, formulación de interrogantes y lecturas adicionales.

Las estrategias para el aprendizaje significativo apuntan a que el estudiante pueda "organizar o integrar el nuevo conocimiento [...] para que este aprenda con mayor eficacia los contenidos curriculares y extracurriculares que se le presentan" (p. 115). Según el tipo de proceso cognitivo (Pozo, 1990) estas estrategias pueden ser de elaboración o de organización. Las de elaboración tienen que ver con la interacción entre la nueva información con los conocimientos previos del estudiante. Estas

permiten un tratamiento y una codificación más sofisticados de la información que se ha de aprender, porque atienden de manera básica a su significado y no a sus aspectos superficiales. [...] La idea fundamental no es reproducir simplemente la información aprendida sino ir más allá, con la elaboración u organización 
del contenido; esto es, descubriendo y construyendo significados para encontrar sentido en la información (Barriga Acero y Hernández Rojas, 1999, pp. 119-120).

Dentro de tales estrategias, se pueden citar: consultas bibliográficas, la creación de imágenes mentales, de conceptos -y su representación en dibujos, esquemas o textos-, el parafraseo, la elaboración de inferencias, de resúmenes, y las analogías.

Las estrategias de organización facilitan una reorganización constructiva de la información por aprenderse. Además, con las estrategias mencionadas, se pretendió que el estudiante encontrara sentido a la información aprendida y la utilizara. Dentro de estas, se pueden citar: el uso de categorías, la resolución, el análisis individual/grupal de ejercicios, de cuestionarios; la preparación y presentación de exposiciones; la elaboración de mapas conceptuales y mentales, de ilustraciones, de resúmenes, el uso de estructuras, de tipos textuales; la realización de trabajos en grupo, de role-playing, de videos, de pruebas de ejecución. Estas pruebas tienen que ver con la preparación y realización de actividades reales 0 , si no es posible, de actividades simuladas "en donde los aprendices ejecutan las habilidades técnicas o aplican conocimientos aprendidos (v. gr. [...] escribir un texto, [...] ejecutar una estrategia cognitiva” (Barriga Acero y Hernández Rojas, 1999, p. 198), y prácticas que los alumnos realizan en clase o fuera de esta.

En el proceso pedagógico, se apuntó a que el estudiante manejara y construyera conocimiento, a partir de su participación activa en las 11 actividades propuestas. En tales actividades, el alumno: organizó conceptos e ideas; elaboró y sustentó diversos tipos de trabajos ya orales ya escritos. Así mismo, los compañeros de clase -al interactuar unos con otros en las diversas actividades desarrolladas- se constituyeron, igualmente, en mediadores y partícipes en la construcción de conocimiento. Desde las primeras clases, el profesor empezó a indagar los conocimientos que los educandos tenían, sobre información, aspectos o temáticas sobre Lingüística general a través de observaciones; de lluvia de ideas; de la formulación de preguntas; de la elaboración y aplicación de cuestionarios y ejercicios; del diseño y aplicación de situaciones; de las actividades y de los trabajos realizados por los estudiantes. Cuando los educandos no poseían conocimientos relevantes sobre un tema de lingüística o los había olvidado, el profesor elaboró lecturas y glosarios con los cuales ayudó al estudiante para que pudiera establecer un vínculo entre lo que él sabía y lo que debía saber sobre temáticas de lingüística. El alumno recibía una información nueva dada, generalmente, por el docente (p. ej.: lecturas seleccionadas, resúmenes, glosarios) o consultada por ellos. El educando - a través de su participación dinámica en las diversas actividades propuestas- la relacionaba con su estructura cognitiva. Para promover la relación entre la información previa con la nueva en los alumnos, el profesor recurrió al uso de organizadores previos, a la presentación de unas analogías, a la formulación de 
interrogantes y a varias lecturas adicionales, y tuvo presente intereses de los educandos. El estudiante procesó, activamente, la información, descubrió y creó nuevas ideas. Fue, en esta interacción -información nueva con la información relevante ya depositada-, en la cual el conocimiento previo del estudiante se iba modificando, y, gracias a la cual se esperaba que el estudiante integrara, estructurara y creara una información que le fuera útil para aplicarla, en especial, en su contexto académico de la licenciatura en Lenguas Extranjeras, y que le sirviera, en el futuro, para su labor como docente.

\subsection{Tres categorías de análisis de lo ocurrido en su puesta en acción en el aula}

Se presentan tres categorías de análisis -a partir de algunos de los principios del aprendizaje significativo presentados- de lo sucedido en su puesta en acción en el aula durante el desarrollo de las actividades: la primera hace referencia a la articulación no arbitraria y sustantiva entre la nueva información -temáticas de la cátedra de lingüística general- con la que el estudiante ya posee. En esta categoría, se menciona la forma como los estudiantes relacionaron lo que sabían o iban aprendiendo con los nuevos contenidos que se les daban a conocer en la cátedra, mediante, por ejemplo, organizadores previos; relaciones de subordinación; supraordenación, y aprendizaje combinatorio. Así mismo, a la manera como ellos integraron, estructuraron y crearon información que les fuera útil para aplicarla, en especial, en su contexto académico. Dentro de esta primera categoría, también se alude a cómo el profesor programó y organizó los contenidos de la cátedra de linguística general, teniendo presente la diferenciación progresiva, la reconciliación integrativa, la organización secuencial y la consolidación. Igualmente, se enuncian las estrategias de elaboración y las de organización de la información, utilizadas por los educandos, al llevar a cabo las actividades.

La segunda categoría tiene que ver con el desempeño activo del estudiante en el desarrollo de las once actividades. En esta, se explicita la participación dinámica del estudiante al relacionar contenidos de la cátedra con sus conocimientos; al procesar, asimilar y retener esta información, y al construir, plantear y aplicar ideas nuevas. En la tercera categoría, se hace referencia a la función orientadora del docente en el proceso pedagógico, con el propósito de que el discente aprendiera y utilizara la información relacionada con las temáticas de la cátedra. Finalmente, la cuarta categoría apunta a cómo las actividades realizadas posibilitaron la consecución de un mejor nivel de aprendizaje significativo de los temas de lingüística general en el educando. 


\subsection{Actividades pedagógicas}

Estas hacen referencia a los diversos trabajos, dinámicas, estrategias académicas, y formas de evaluación que se plantearon y aplicaron en tal trabajo investigativo, con el propósito de que el alumno de la cátedra de Lingüística general, se apropiara, de manera motivante y divertida, de unos contenidos básicos.

Dentro de las actividades es de citar algunas, como: lecturas de textos sobre temáticas lingüísticas -comprensión e interpretación de las mismas-; realización de una serie de ejercicios; talleres; conversatorios; trabajos prácticos, creación y presentación de sketchs; diseño y elaboración de textos pedagógicos; propuesta, montaje y presentación de productos audiovisuales, y de ejercicios en donde el discente aplica los constructos teóricos analizados, y, además, postula sus ideas, visiones y planteamientos, no solo desde una visión individual sino, además, -en varias ocasiones- desde una grupal.

Las actividades pedagógicas apuntaron a: crear un clima armónico donde el alumno sintiera confianza en donde él pudiera organizar, relacionar e incorporar lo aprendido con lo nuevo por aprender; construyera e intercambiara ideas; pudiera crear y explicar mediante ejemplos; llevara a la práctica -a través de la actividad y el trabajo en clase, la competencia y la cooperación con los demás compañeros- 0 aprendido para que este conocimiento fuera asimilado y se lograra un aprendizaje adecuado. Al participar en las actividades, el estudiante realizó una interacción entre lo que ya sabía y las temáticas de la asignatura; elaboró y organizó el contenido; construyó y aprendió el significado de las temáticas y no se limitó a aprender "al pie de la letra" ni a reproducir información. Complementario a lo anterior, las actividades permitieron una reorganización de la nueva información; en estas, el alumno, p.ej.: usó categorías; desarrolló y analizó ejercicios tanto individual como grupalmente; preparó y sustentó exposiciones; elaboró mapas mentales, ilustraciones, resúmenes, diversos tipos textuales y videos.

\section{Marco metodológico}

La población estuvo compuesta por los dos grupos de estudiantes de la cátedra de Lingüística general del Programa de Licenciatura en Lenguas Extranjeras (aproximadamente, 70 estudiantes), en el segundo semestre académico de 2013. El Programa está adscrito a la Facultad de Ciencias de la Educación de la Universidad Pedagógica y Tecnológica de Colombia. La muestra está conformada por el grupo 05 (32 estudiantes) de la cátedra de Lingüística general del Programa mencionado.

El trabajo se enmarcó en un tipo de investigación aplicada, puesto que esta es "práctica, pone a prueba la teoría $[y]$ aclara conceptos [...] [su] objetivo [...] es buscar 
soluciones a los problemas mediante la aplicación [...] de la teoría; [además,] puede aportar hechos nuevos"(Camacho de Báez, 2003, pp. 61-65), y se situó dentro del diseño investigativo del enfoque cualitativo, denominado: Investigación-acción, ya que el trabajo se desarrolló en el contexto universitario -cátedra de Lingüística general-, y se realizó con el propósito de dar una alternativa de solución - a partir de la concepción y aplicación de una serie de actividades pedagógicas- a una problemática: precisamente, la ausencia de este tipo de actividades que propicien un acercamiento y apropiación pertinentes de temas básicos abordados en la cátedra de Lingüística general. En el desarrollo de las actividades, se tuvo en cuenta la colaboración y participación activa de los estudiantes del grupo 05 (generalmente, existen dos grupos de discentes), como actores dinámicos, destinatarios y beneficiarios principales.

En este estudio, se tuvo presente los ciclos/momentos de la Investigación-acción (de acuerdo con Sandín, 2003, citado por Hernández Sampieri et al., 2010, p. 512), para los ciclos, y con Castillo Durán et al. (2001, pp. 78-82), paralos momentos): 1er. ciclo: detectar el problema de investigación/ 1er. momento: la exploración y la reflexión. El docente realizó una inmersión inicial en el contexto de la cátedra de Linguiística general. Allí, él detectó una problemática: la ausencia de actividades pedagógicas pertinentes que propicien un acercamiento y apropiación adecuados de ciertos temas de la cátedra de Lingüística general, por parte del grupo 05 de estudiantes; luego, se procedió al planteamiento y formulación de dicha problemática. Enseguida, el docente reflexionó en la generación 0 postulación de una propuesta de estrategia de acción (hipótesis) en orden a solucionar el problema: la creación, diseño y aplicación de 11 actividades pedagógicas, a través de las cuales se lograra un acercamiento y una apropiación pertinente de temas estudiados en la cátedra. $2^{\circ}$. ciclo: elaborar el plan para resolver el problema $/ 2^{\circ}$. momento: planificación: el profesor elaboró un plan para el diseño y aplicación de las actividades pedagógicas. 3er. ciclo Implementar y evaluar el plan/ 3er. momento: la acción y la observación: el docente, en el desarrollo de la cátedra de Lingüística general, implementó, observó y evaluó el plan diseñado (aplicación y desarrollo de las actividades pedagógicas). El profesor observó, identificó, recogió y registró, en el diario de campo, aspectos relacionados con la aplicación del plan: los efectos, aspectos por resaltar (a manera de fortalezas); aspectos por mejorar (a manera de debilidades), circunstancias, aciertos, limitaciones, y aspectos para reflexionar, y $4^{\circ}$ ciclo: realimentación $/ 4^{\circ}$ momento: la evaluación. El docente reflexionó y evaluó durante el desarrollo de las actividades, ya fuera para "seguir por este sendero" o para realizar los ajustes necesarios (acción observada). 


\section{De las actividades pedagógicas realizadas}

Se propone una síntesis de las actividades realizadas para propiciar un acercamiento y apropiación pertinente de unos temas básicos, abordados en la cátedra de Lingüística general. Es de aclarar que nueve actividades fueron creadas por el autor de este artículo. Las actividades: "un día en la vida de un lingüista: presentación de un lingüista", y "Noam Chomsky, unos términos de su teoría lingüística y formas creativas para darlos a conocer a "mis alumnos del colegio"”, se diseñaron en coautoría con el profesor César Augusto Romero Farfán, director de la Escuela de Idiomas, de la Uptc. A continuación, se presenta un cuadro que contiene la síntesis de las actividades planteadas en el trabajo investigativo.

Tabla.$^{0}{ }^{2}$. Síntesis de las actividades propuestas y aplicadas

\begin{tabular}{|c|c|c|c|}
\hline Tema & $\begin{array}{c}\text { Nombre de la } \\
\text { Actividad }\end{array}$ & Objetivo & Descripción \\
\hline $\begin{array}{l}\text { 1. Perspectivas } \\
\text { en el estudio } \\
\text { del lenguaje: } \\
\text { prescriptiva, } \\
\text { descriptiva, } \\
\text { explicativa }\end{array}$ & $\begin{array}{l}\text { 1. Acercándonos } \\
\text { a tres actitudes en } \\
\text { los estudios del } \\
\text { lenguaje. }\end{array}$ & $\begin{array}{l}\text { Lograr que los } \\
\text { estudiantes } \\
\text { de la cátedra } \\
\text { de Linguíística } \\
\text { general consigan } \\
\text { un acercamiento } \\
\text { a tres actitudes } \\
\text { en los estudios } \\
\text { del lenguaje: } \\
\text { Prescriptiva, } \\
\text { Descriptiva y } \\
\text { Explicativa. }\end{array}$ & $\begin{array}{l}\text { El profesor anota, en el tablero, las palabras: lenguaje; } \\
\text { prescriptivo; descriptivo y explicativo con el fin de } \\
\text { provocar, en los estudiantes, una lluvia de ideas; } \\
\text { posteriormente, les formula unas preguntas a partir de } \\
\text { situaciones -en donde se hallan las tres perspectivas } \\
\text { en el estudio del lenguaje- para identificar los saberes } \\
\text { previos del alumno sobre este tema. Enseguida, el } \\
\text { docente realiza una orientación teórica sobre el tema. } \\
\text { Él presenta algunas diapositivas con la información } \\
\text { pertinente. Posteriormente, distribuye, a los alumnos, } \\
\text { un material sobre algunos constructos teóricos acerca } \\
\text { de estas actitudes. Los estudiantes lo leen, lo analizan } \\
\text { y formulan preguntas. Los compañeros y el docente } \\
\text { participan en la solución a dichos interrogantes. } \\
\text { Luego, los alumnos desarrollan un ejercicio sobre este } \\
\text { tema. Finalmente, docente y alumnos intercambian } \\
\text { información sobre dicho desarrollo. }\end{array}$ \\
\hline $\begin{array}{l}\text { 2. Conceptos } \\
\text { operativos }\end{array}$ & $\begin{array}{l}\text { 2. Unos conceptos } \\
\text { operativos en } \\
\text { linguística general } \\
\text { y "mi miniclase" }\end{array}$ & $\begin{array}{l}\text { Lograr que los } \\
\text { estudiantes } \\
\text { de la cátedra } \\
\text { de Linguística } \\
\text { general consigan } \\
\text { un acercamiento } \\
\text { a tres actitudes } \\
\text { en los estudios } \\
\text { del lenguaje: } \\
\text { Prescriptiva, } \\
\text { Descriptiva y } \\
\text { Explicativa. }\end{array}$ & $\begin{array}{l}\text { El profesor entrega un cuestionario sobre unos conceptos } \\
\text { operativos en el estudio del lenguaje humano y los } \\
\text { estudiantes lo responden. A continuación, el docente les } \\
\text { entrega un glosario sobre unos conceptos operativos. Los } \\
\text { alumnos comparan sus respuestas con las definiciones } \\
\text { presentadas en el glosario para comprobar que han } \\
\text { respondido adecuadamente o, de ser necesario, para } \\
\text { realizar los ajustes, las modificaciones y correcciones. } \\
\text { Luego, el profesor les solicita parafrasear y ejemplificar } \\
\text { los conceptos abordados. Los estudiantes dan a conocer } \\
\text { el trabajo realizado; los compañeros colaboran dando } \\
\text { su aprobación si el trabajo es correcto o, en caso } \\
\text { contrario, manifestando su desacuerdo y proponiendo la } \\
\text { corrección pertinente. Finalmente, el profesor informa } \\
\text { y solicita a los discentes realizar el trabajo grupal: Mi } \\
\text { miniclase: tres conceptos operativos y la explicación } \\
\text { pedagógica de los mismos. }\end{array}$ \\
\hline
\end{tabular}




\begin{tabular}{|c|c|c|c|}
\hline Tema & $\begin{array}{c}\text { Nombre de la } \\
\text { Actividad }\end{array}$ & Objetivo & Descripción \\
\hline $\begin{array}{l}\text { 3. Historia } \\
\text { general de la } \\
\text { Lingüística }\end{array}$ & $\begin{array}{l}\text { 3. Un poquito } \\
\text { de Historia } \\
\text { general sobre la } \\
\text { lingüística, no } \\
\text { hace daño. }\end{array}$ & $\begin{array}{l}\text { Posibilitar, en los } \\
\text { estudiantes de } \\
\text { la cátedra, una } \\
\text { aproximación } \\
\text { a información } \\
\text { sobre historia } \\
\text { de la lingüística } \\
\text { (visión general) } \\
\text { y conseguir una } \\
\text { apropiación de } \\
\text { tal información. }\end{array}$ & $\begin{array}{l}\text { El profesor entrega a los alumnos el texto: capítulos: I, Aparición } \\
\text { del lenguaje, y II en la antigüedad, del texto: "Historia general } \\
\text { de la Lingüística. Desde Panini hasta Ferdinand de Saussure, } \\
\text { 1916", de Samuel Estrada Duque. Cali: Universidad del Valle, } \\
\text { 1998) para que lo estudien. Luego, el maestro les entrega } \\
\text { un glosario con las definiciones y aclaraciones sobre algunos } \\
\text { de los términos mencionados en el texto. Posteriormente, el } \\
\text { docente realiza un conversatorio en donde los alumnos dan } \\
\text { a conocer aspectos de la lectura y presentan un resumen y } \\
\text { sus impresiones sobre tal lectura; el profesor, cuando sea } \\
\text { pertinente, efectúa orientaciones y aclaraciones. Enseguida, } \\
\text { los estudiantes elaboran y explican un mapa mental sobre la } \\
\text { historia general de la lingüística. Finalmente, se les pide realizar } \\
\text { el trabajo grupal: la historia de la linguiística y habilidades del } \\
\text { grupo de trabajo. En este, cada uno de los subgrupos de trabajo } \\
\text { presentará un apartado del texto abordado, a partir de, por } \\
\text { ejemplo: un juego didáctico; un juego de roles; la creación y } \\
\text { presentación de canciones, de programas de tv, etc. }\end{array}$ \\
\hline $\begin{array}{l}\text { 4. Campos y } \\
\text { disciplinas de la } \\
\text { linguiística }\end{array}$ & $\begin{array}{l}\text { 4. Un viaje } \\
\text { interesante por } \\
\text { los Campos y } \\
\text { disciplinas de la } \\
\text { lingüistica, la } \\
\text { creatividad, los } \\
\text { mapas mentales } \\
\text { y el material } \\
\text { reciclable. }\end{array}$ & $\begin{array}{l}\text { Lograr que los } \\
\text { alumnos se } \\
\text { apropien de } \\
\text { información } \\
\text { relacionada con } \\
\text { los Campos y } \\
\text { disciplinas de la } \\
\text { lingüística. }\end{array}$ & $\begin{array}{l}\text { Como trabajo en casa, los alumnos consultan, en textos } \\
\text { impresos y virtuales, sobre los campos y disciplinas de la } \\
\text { lingüística; en clase, se realiza una mesa redonda en donde } \\
\text { los alumnos exponen oralmente aspectos del trabajo de } \\
\text { consulta realizado; los compañeros y el profesor, en caso } \\
\text { necesario, complementarán, ampliarán o rectificarán los } \\
\text { aspectos teóricos en cada una de las intervenciones; luego, los } \\
\text { educandos abordan el texto denominado: Campos y disciplinas } \\
\text { de la lingüística. En: Niño Rojas, Víctor Miguel. Semiótica y } \\
\text { lingüística aplicadas al Español. Colombia: Ecoe (2002. pp. } \\
\text { 117-122.). Enseguida, se dan un espacio para dialogar sobre } \\
\text { el texto y para formular comentarios, preguntas e inquietudes. } \\
\text { A continuación, los alumnos, en pares, desarrollan un ejercicio } \\
\text { sobre la temática estudiada. Como trabajo en casa, el estudiante } \\
\text { procede a: elaborar un esquema creativo, utilizando material } \\
\text { reciclable, en donde presente, de manera general y completa, } \\
\text { lo planteado en el texto mencionado. En la siguiente clase, los } \\
\text { estudiantes llevan a cabo la "sensacional exposición creativa } \\
\text { sobre campos y disciplinas de la lingüística"; luego de dar } \\
\text { a conocer su trabajo artístico, los compañeros de clase le } \\
\text { formulan interrogantes al autor sobre el esquema realizado y su } \\
\text { relación con aspectos propuestos en el texto; sobre el porqué } \\
\text { del diseño, de los materiales escogidos y sobre la significación } \\
\text { de su trabajo artístico. }\end{array}$ \\
\hline $\begin{array}{l}\text { 5. Presentación } \\
\text { de un lingüista }\end{array}$ & $\begin{array}{l}\text { 5. Un día en } \\
\text { la vida de } \\
\text { un lingüista: } \\
\text { presentación de } \\
\text { un lingüista }\end{array}$ & $\begin{array}{l}\text { Acercar a los } \\
\text { estudiantes a } \\
\text { unos aspectos de } \\
\text { la vida y obra de } \\
\text { varios lingüistas }\end{array}$ & $\begin{array}{l}\text { El estudiante, luego de la consultay el trabajo de documentación, } \\
\text { escoge dos nombres de dos lingüistas. Posteriormente, } \\
\text { el alumno elige uno; presenta un guión, en el cual se da } \\
\text { información sobre: a) Biografía (Lugar-año-nacimiento/ } \\
\text { muerte). b) } 5 \text { ideas sobre la postura teórica del lingüista y c) El } \\
\text { título de una obra del lingüista escogido. El lingüista escogido } \\
\text { se presenta, utilizando dos objetos (vestuario, u otro) que } \\
\text { represente o se relacione, correctamente, con la vida y con la } \\
\text { propuesta teórica planteada por el lingüista. La presentación de } \\
\text { la información se realiza en forma oral (uso del micrófono), } \\
\text { ante los compañeros de clase. }\end{array}$ \\
\hline
\end{tabular}




\begin{tabular}{|c|c|c|c|}
\hline Tema & $\begin{array}{l}\text { Nombre de la } \\
\text { Actividad }\end{array}$ & Objetivo & Descripción \\
\hline $\begin{array}{l}\text { 6. Las lenguas del } \\
\text { mundo visitan mi } \\
\text { colegio }\end{array}$ & $\begin{array}{l}\text { 6. Las lenguas del } \\
\text { mundo visitan mi } \\
\text { colegio }\end{array}$ & $\begin{array}{l}\text { Facilitar en los } \\
\text { estudiantes, la } \\
\text { apropiación de } \\
\text { unas características } \\
\text { de varias lenguas } \\
\text { del mundo para } \\
\text { que ellos las den } \\
\text { a conocer a "sus } \\
\text { alumnos". }\end{array}$ & $\begin{array}{l}\text { En clases anteriores, el profesor deja, a los estudiantes, } \\
\text { un texto y dos ejercicios sobre las lenguas del mundo (A } \\
\text { partir de lo propuesto en: López García, Ángel y otros. } \\
\text { Linguística general y aplicada. Valencia: Universitat } \\
\text { de Valencia, 1999, pp. 15-27, y 34-38) para que } \\
\text { ellos realicen la lectura respectiva y desarrollen, por } \\
\text { parejas, el primer ejercicio planeado, y, lleven a cabo, } \\
\text { por grupos, el segundo. En clase, discentes y docente } \\
\text { comparten ideas sobre el texto leído, y conversan sobre } \\
\text { el desarrollo de los dos ejercicios. Luego, el docente les } \\
\text { da a conocer las orientaciones sobre el trabajo grupal: } \\
\text { Las lenguas del mundo visitan mi colegio. En este } \\
\text { trabajo los alumnos preparan y realizan una "miniclase" } \\
\text { (actividad simulada), dirigida a un grupo de estudiantes } \\
\text { de uno de los grados de educación básica. }\end{array}$ \\
\hline $\begin{array}{l}\text { 7. Ferdinand de } \\
\text { Saussure y el } \\
\text { estructuralismo } \\
\text { lingüístico }\end{array}$ & $\begin{array}{l}\text { 7. Ferdinand de } \\
\text { Saussure, y textos } \\
\text { escolares }\end{array}$ & \begin{tabular}{|l|} 
Propiciar, en los \\
estudiantes, un \\
acercamiento y \\
apropiación de unos \\
datos sobre la vida \\
y obra de Ferdinand \\
de Saussure, y sobre \\
unas generalidades \\
del estructuralismo \\
lingüístico.
\end{tabular} & $\begin{array}{l}\text { Como trabajo en casa, los alumnos elaboran su biografía, } \\
\text { en esta incluyen su proyección y sus planteamientos } \\
\text { como futuros lingüistas. Así mismo, redactan un } \\
\text { texto breve donde dan a conocer qué entienden por } \\
\text { estructuralismo lingüístico. El profesor, previamente, } \\
\text { deja, a los estudiantes, unos textos sobre la vida y obra } \\
\text { de Ferdinand de Saussure, y sobre el estructuralismo } \\
\text { linguístico, y un ejercicio sobre este tema, para que } \\
\text { ellos lo desarrollen. En clase, los alumnos dan a a } \\
\text { conocer el desarrollo del ejercicio. Los compañeros de } \\
\text { clase -y si es necesario el profesor- pueden proponer } \\
\text { aclaraciones, comentarios y sugerencias pertinentes. } \\
\text { A continuación, los alumnos elaboran un cuadro } \\
\text { sinóptico de la información de los textos estudiados. } \\
\text { Posteriormente, ellos comparan su biografía y su } \\
\text { concepción sobre estructuralismo linguístico con lo } \\
\text { planteado en el texto sobre la biografía de Saussure y el } \\
\text { estructuralismo linguístico para hallar posibles puntos } \\
\text { de encuentro y/o diferencias; finalmente, elaboran un } \\
\text { comentario al respecto y lo exponen a los compañeros. } \\
\text { Enseguida, el maestro les entrega un texto y un ejercicio } \\
\text { sobre las relaciones paradigmáticas y sintagmáticas } \\
\text { (de acuerdo con lo propuesto por Raúl Ávila, pp. } 52- \\
58 \text { En: Ávila Raúl. La lengua y los hablantes. México: } \\
\text { Trillas, 2003). Después, les entrega un glosario con } \\
\text { las definiciones y aclaraciones sobre algunos de los } \\
\text { términos mencionados en el texto de Raúl ávila; luego, } \\
\text { se realiza un breve conversatorio sobre el tema. Para } \\
\text { finalizar, el profesor da a conocer las orientaciones del } \\
\text { trabajo grupal: El Texto escolar y Ferdinand de Saussure. } \\
\text { En este, los alumnos escogen } 8 \text { de los términos vistos; } \\
\text { elaboran y realizan el lanzamiento de un texto escolar } \\
\text { dirigido a un grado de educación básica. }\end{array}$ \\
\hline
\end{tabular}




\begin{tabular}{|c|c|c|c|}
\hline Tema & $\begin{array}{c}\text { Nombre de la } \\
\text { Actividad }\end{array}$ & Objetivo & Descripción \\
\hline $\begin{array}{l}\text { 8. Unos datos } \\
\text { biográficos } \\
\text { de Chomsky y } \\
\text { sobre aspectos } \\
\text { fundamentales } \\
\text { del } \\
\text { pensamiento } \\
\text { chomskiano }\end{array}$ & $\begin{array}{l}\text { 8. Noam } \\
\text { Chomsky, } \\
\text { unos términos } \\
\text { de su teoría } \\
\text { lingüística } \\
\text { y formas } \\
\text { creativas } \\
\text { para darlos a } \\
\text { conocer a "mis } \\
\text { alumnos del } \\
\text { colegio". }\end{array}$ & $\begin{array}{l}\text { Conseguir que } \\
\text { los alumnos } \\
\text { de la cátedra } \\
\text { identifiquen } \\
\text { y manejen, } \\
\text { adecuadamente, } \\
\text { unos términos } \\
\text { de la teoría } \\
\text { chomskiana, y } \\
\text { generen formas } \\
\text { creativas y } \\
\text { didácticas para } \\
\text { darlos a conocer. }\end{array}$ & $\begin{array}{l}\text { Noam Chomsky (caracterizado por el docente) -como invitado } \\
\text { especial a la cátedra de Lingüística general- da a conocer } \\
\text { unos datos biográficos y unos aspectos fundamentales de su } \\
\text { pensamiento y les entrega un texto sobre este tema. Los estudiantes } \\
\text { elaboran un resumen sobre ciertos aspectos teóricos básicos de } \\
\text { la propuesta chomskiana. Después, los estudiantes desarrollan un } \\
\text { ejercicio sobre este tema. Después, pueden formular preguntas, } \\
\text { consideraciones y opiniones sobre el ejercicio. Los compañeros } \\
\text { de clase pueden postular respuestas a las preguntas que surjan; } \\
\text { si es necesario, interviene el profesor. Finalmente, el docente da } \\
\text { a conocer las orientaciones del trabajo en casa: los educandos } \\
\text { releen el texto -entregado por el profesor en la parte inicial de } \\
\text { la clase- sobre planteamientos de la propuesta chomskiana, } \\
\text { así mismo, repasan los textos vistos en las clases anteriores; } \\
\text { luego, elaboran una gráfica en donde establecen y representan } \\
\text { cuáles planteamientos, ideas o propuestas ha retomado Noam } \\
\text { Avram Chomsky de otros estudiosos para la conformación de su } \\
\text { teoría. Así mismo, el profesor presenta los parámetros para la } \\
\text { realización del trabajo sobre unos conceptos básicos de la teoría } \\
\text { chomskiana. En este trabajo, los alumnos, por pares, deben } \\
\text { explicar en forma creativa y didáctica un concepto de esta teoría } \\
\text { a los compañeros de clase. }\end{array}$ \\
\hline $\begin{array}{l}\text { 9. Teun A. } \\
\text { Van Dijk y la } \\
\text { textolingüística }\end{array}$ & $\begin{array}{l}\text { 9. De Teun A. } \\
\text { Van Dijk y la } \\
\text { textolingüística, } \\
\text { a la producción } \\
\text { de comerciales } \\
\text { creativos. }\end{array}$ & $\begin{array}{l}\text { Permitir, en los } \\
\text { estudiantes, la } \\
\text { aproximación y } \\
\text { la apropiación } \\
\text { de información } \\
\text { sobre la vida y } \\
\text { obra de Teun Van } \\
\text { Dijk, y sobre unos } \\
\text { aspectos generales } \\
\text { de su propuesta } \\
\text { en relación con la } \\
\text { textolingüística. }\end{array}$ & $\begin{array}{l}\text { El docente les da a conocer aspectos biográficos de Teun A. Van } \\
\text { Dijk y explica unos aforismos preliminares de la linguiística del } \\
\text { texto. Además, él explica unas diapositivas sobre tres niveles de } \\
\text { análisis y producción textual. Los alumnos toman nota y elaboran } \\
\text { un resumen sobre estos aspectos teóricos. Posteriormente, ellos } \\
\text { desarrollan unos ejercicios sobre los tres niveles mencionados. El } \\
\text { docente explica las orientaciones del trabajo grupal: "Creatividad } \\
\text { y una temática de Teun A. Van Dijk, y la Textolingüística". En } \\
\text { este trabajo, los alumnos deben idear, grabar, editar y lanzar un } \\
\text { corto fílmico donde presenten una temática asignada la cual hace } \\
\text { referencia a uno de los aspectos de la propuesta teórica de Teun } \\
\text { Van Dijk. }\end{array}$ \\
\hline $\begin{array}{l}\text { 10. Concurso: } \\
\text { Campeón en } \\
\text { lingüística } \\
\text { general }\end{array}$ & $\begin{array}{l}\text { 10. CONCURSO: } \\
\text { Campeón en } \\
\text { lingüística } \\
\text { general }\end{array}$ & $\begin{array}{l}\text { Lograr que los } \\
\text { estudiantes } \\
\text { realicen un repaso } \\
\text { de los temas vistos } \\
\text { en la cátedra de } \\
\text { lingüística general }\end{array}$ & $\begin{array}{l}\text { Cada uno de los alumnos elabora un texto creativo (cuento, } \\
\text { receta de cocina, adivinanzas, carta romántica, etc.). El alumno } \\
\text { debe recurrir a uno o a varios de los temas vistos en la cátedra } \\
\text { de Lingüística general como base teórica para la elaboración de } \\
\text { dicho texto. Seguidamente, los estudiantes elaboran el tipo de } \\
\text { texto escogido. Si lo requieren, ellos pueden formular preguntas o } \\
\text { solicitar la orientación del profesor en el proceso de elaboración } \\
\text { del texto. Luego de finalizado el proceso, los estudiantes se } \\
\text { reúnen en grupos. Cada uno de los integrantes de los grupos } \\
\text { conformados, lee su texto ante los demás. Los integrantes del } \\
\text { subgrupo eligen el texto ganador; es decir, el escrito que presenta } \\
\text { de manera más interesante y creativa la (o las) temática(s) de la } \\
\text { cátedra de linguística general, escogida(s) por el autor del texto. } \\
\text { El profesor solicita a los autores de los textos ganadores leer su } \\
\text { creación ante todo el grupo. El grupo escucha, atentamente, y } \\
\text { elige, por medio de votación, el texto “CAMPEÓNENLINGÜÍSTICA } \\
\text { GENERAL”. Se realiza el reconocimiento y la premiación a cada } \\
\text { uno de los textos finalistas, y al texto ganador. }\end{array}$ \\
\hline
\end{tabular}




\begin{tabular}{|l|l|l|l|}
\hline \multicolumn{1}{|c|}{ Tema } & $\begin{array}{l}\text { Nombre de la } \\
\text { Actividad }\end{array}$ & \multicolumn{1}{c|}{ Objetivo } & \multicolumn{1}{c|}{ Descripción } \\
\hline $\begin{array}{l}\text { 11. Hacia un } \\
\text { repaso de los } \\
\text { temas vistos } \\
\text { en la cátedra } \\
\text { de lingüística } \\
\text { general }\end{array}$ & $\begin{array}{l}\text { 11. Concursando, } \\
\text { ando, con la } \\
\text { lingüística } \\
\text { general }\end{array}$ & $\begin{array}{l}\text { Lograr que los } \\
\text { estudiantes realicen } \\
\text { un repaso de } \\
\text { los temas vistos } \\
\text { en la cátedra de } \\
\text { lingüística general. }\end{array}$ & $\begin{array}{l}\text { Cada uno de los grupos conformados crea y realiza, } \\
\text { durante un determinado tiempo, un concurso en } \\
\text { donde logre, en lo posible, la participación de todos los } \\
\text { compañeros de la cátedra de lingüística general, o la de } \\
\text { algunos de ellos. El concurso se basará en los temas vistos } \\
\text { en la cátedra de Lingüística general. Se deben formular } \\
\text { preguntas, actividades, juegos, etc., relacionados con tales } \\
\text { temas. Las reglas del concurso deben ser claras (selección, } \\
\text { participación, ganadores, penitencias, premiación, etc.). }\end{array}$ \\
\hline
\end{tabular}

\section{Resultados}

Al ser esta una investigación de corte cualitativo, los resultados se construyeron a partir de la información suministrada, principalmente, en el desarrollo de cada una de las 11 actividades; en las observaciones de clase y en unas conversaciones espontáneas con algunos alumnos antes, durante 0 al finalizar las clases; esta información se registró, en buena medida, en el diario de campo (aspectos por resaltar; aspectos por mejorar y aspectos para reflexionar). En un vistazo general a los resultados, se puede mencionar lo siguiente:

\subsection{De la articulación no arbitraria y sustantiva entre la nueva información con la que el estudiante ya posee respecto de las temáticas de la cátedra de lingüística general.}

En ciertos temas, unos estudiantes disponían de pocos conocimientos precedentes; por esto, en algunas oportunidades, se recurrió a la estrategia de los organizadores previos: se les dio unas lecturas, unas explicaciones y unos glosarios que sirvieran de punto de anclaje entre conocimiento previo y la nueva información de temas de lingüística por aprender. En este sentido, un estudiante afirma:

"La introducción [explicación] de los temas que el profesor hizo antes de que el estudiante tuviera que estudiar o explicar un tema 0 realizar las actividades propuestas porque $[\ldots]$ así cada alumno tenía la idea más clara y podía así hacer sus presentaciones del tema de una manera mas (sic) segura y logrando que sus compañeros comprendieran el tema". (Diario de campo. Encuesta aplicada a los estudiantes).

De otra parte, el maestro activó conocimientos previos de los educandos, al darles a conocer los objetivos de las actividades; al presentarles glosarios y al formularles ciertos interrogantes. Él orientó su proceso pedagógico, principalmente, a que los estudiantes, con 
su participación activa en el proceso, establecieran relaciones pertinentes entre la nueva información (conceptos, proposiciones, contenidos) de lingüística general y la que hacía parte de su estructura cognitiva, a través de, por ejemplo: Relaciones de subordinación. En cuanto asimilaciones derivativas -los estudiantes incorporaron nueva información como un ejemplo, como una derivación de la información que ya poseían; es así como un estudiante, verbi gracia, comenta ante el profesor y los compañeros: "profe, o sea, que la ortografía se debe situar dentro de la actitud prescriptiva" (actividad 1). Otro estudiante, sitúa el idiolecto del personaje mexicano Cantinflas, dentro de la categoría del Mesolecto.

Respecto de la asimilación correlativa, los estudiantes vincularon, en ciertas oportunidades, la nueva información como una extensión o modificación de los conocimientos que ya poseían; esto se dio, por ejemplo, en la segunda actividad, -respuesta al punto 6 del ejercicio planteado- cuando unos estudiantes presentaron su interesante creación y significación de varios términos usados por ellos, para ejemplificar términos, como: jerga 0 argot; p. ej.: "Antichévere: persona aburrida"; "Bombero: persona que genera confrontación"; "Chafa: Expresión usada para decir que algo no está bien"; "fariseo: traidor"; "Pasta: bueno, qué bien"; "dar lata: fastidiar". En la misma actividad, algunos estudiantes, realizaron una extensión o modificación de la información referente a la "lingüística aplicada" al relacionar lo referente a los campos y disciplinas de la lingüística con su futura labor docente como profesores de lenguas extranjeras; una estudiante afirma que:

Respecto de la "Lingüística Aplicada", la considero importante para mi profesión el aprendizaje de las lenguas extranjeras, para poder facilitar el aprendizaje de una segunda lengua en mis alumnos teniendo en cuenta las disciplinas básicas de la lingüística en mi metodología de trabajo; por ejemplo, a la hora de enseñarle a mis alumnos la pronunciación fonética del francés, les explicaría cómo trabaja el aparato fonético en la pronunciación de las distintas vocales del francés, les explicaría las cavidades de estas (sic), y estaría haciendo referencia a la fonética articulatoria que nos habla del uso de los órganos, para la articulación de los fonemas. También cuando les explique, por ejemplo, la estructura de las oraciones del inglés, sujeto, verbo..., les haría referencia acerca del componente morfosintáctico, que estudia la estructura de las palabras y las oraciones (Diario de campo).

En cuanto las relaciones de supraordinación, los estudiantes integraron en ideas, conceptos, más generales, inclusivos, ideas previas más específicas; por ejemplo: los estudiantes, en general, a partir de los conceptos, proposiciones, contenidos e informaciones abordados y aprendidos en clase, construyeron un concepto generalizador, supraordenador: Lingüística general (su objeto de estudio, unos antecedentes, características, representantes y consideraciones sobre tres teorías relevantes). 
El aprendizaje combinatorio se dio, por ejemplo, cuando los integrantes del subgrupo 2 realizaron una interesante analogía entre un vehículo (el producto promocionado) y dos de las bases de la textolingüística: la semántica y la pragmática; así mismo, cuando el subgrupo 7 llevó a cabo el lanzamiento y el comercial, comparando el concepto de texto (desde la perspectiva de la textolingüística) con el mundo de la moda, principalmente, en lo referente al tejido (texto, cohesión textual), (actividad 9).

\subsubsection{La programación y organización de los contenidos abordados en la cátedra de Lingüística general}

En la programación y organización de los contenidos - propuestos en el Programaabordados en la cátedra de Linguística general, se tuvo en cuenta la diferenciación progresiva: se presentaron las temáticas más generales, más inclusivas, al inicio del proceso académico (v. gr.: tres perspectivas en el estudio del lenguaje: prescriptiva, descriptiva, explicativa; unos conceptos operativos en lingüística general; Historia general de la lingüística.) y, progresivamente, se fueron abordando temas más específicos, menos inclusivos (por ejemplo: Disciplinas y campos de la lingüística; unos aspectos de la vida y obra de varios lingüistas; Ferdinand De Saussure, y el estructuralismo Lingüístico, etcétera.); así mismo, se tuvo presente la reconciliación integrativa: los temas se organizaron y propusieron para que se exploraran y establecieran relaciones entre ideas, temáticas y contenidos; similitudes y diferencias (por ejemplo, un alumno estableció relaciones, similitudes y diferencias, entre las perspectivas descriptiva y explicativa en el estudio del lenguaje y los postulados de Ferdinand de Saussure; el estructuralismo, y las propuestas de Noam A. Chomsky, la teoría del generativismo, y los postulados de Teun Van Dijk, y la textolingüística). A más de esto, se recurrió a la organización secuencial: los temas o unidades de estudio se presentaron de manera secuenciada y coherente (teniendo presente lo relacionado con la diferenciación progresiva y de la reconciliación integrativa). Esto, con el propósito de que los temas estudiados y aprendidos en primer lugar, o presentados previamente, se constituyeran en soporte ideacional u organizador; de forma que actuaran como facilitadores del aprendizaje de los estudiantes.

Respecto de la consolidación, -a partir de lo propuesto en nueve de las actividades, y mediante las observaciones, explicaciones, aclaraciones y comentarios hechos por los estudiantes y, en ciertos momentos, por el profesor, durante y al final de las clases- se pretendió que, precisamente, los estudiantes consolidaran y aprendieran, en la mejor forma, cada uno de los contenidos estudiados y, secuencialmente, organizados; esto con el fin de que los temas precedentes fueran aprendidos de manera clara y organizada, antes de abordar un nuevo tema. En las actividades 10 y 11, por ejemplo, los estudiantes -a través 
del diseño y participación en los concursos- repasaron, reforzaron y consolidaron los distintos temas estudiados y aprendidos durante el desarrollo de la cátedra.

\subsubsection{Unas estrategias de aprendizaje: estrategias de elaboración y de organización de la información}

Dentro de las estrategias de elaboración, los educandos utilizaron técnicas 0 habilidades, como: las palabras clave (estas las emplearon, por ejemplo, en los concursos de las actividades 10 y 11); en la creación -y representación en dibujos, esquemas 0 textos- (por ejemplo, en las actividades 4, 5 y 7); así mismo, los estudiantes realizaron parafraseo, en algunos momentos, en las actividades 3 y 5 . En la actividad 3, por ejemplo, varios alumnos parafrasearon, adecuadamente, aspectos sobre la historia de la linguística y -respecto de la actividad 7- dieron a conocer aspectos de la biografía de Saussure, usando sus propias palabras. A más de esto, ellos elaboraron inferencias, -por ejemplo, al establecer y formular la intención de la canción, y al plantear los componentes ideológico y político subyacentes en la canción: "Somos más americanos" (del grupo mexicano, Los tigres del norte) (actividad 9)-; realizaron resúmenes (actividad 8); plantearon las analogías (por ejemplo, cuando los estudiantes establecieron comparaciones entre la cohesión y los tejidos (actividad lanzamiento del comercial) y entre la coherencia y la creación de un medicamento, precisamente para mejorar la conexión de ideas a nivel cerebral (denominado por los estudiantes, como: "La neurocoherencina"), (actividad 9); la creación de conceptos (por ejemplo, cuando los alumnos establecieron y definieron unos conceptos que ellos emplean: "Chafa: Expresión usada para decir que algo no está bien" (respuesta al punto 6 del ejercicio. Actividad 2); diseñaron imágenes visuales simples y complejas (al crear y sustentar p. ej.: carteles, esquemas, mapas mentales, diapositivas y los comerciales); elaboraron y usaron estructuras textuales (tipos textuales), p. ej., en actividad 10; actividad en la cual los alumnos elaboraron un texto creativo (cuento, receta de cocina, adivinanzas, carta romántica, poema, canción, coplas, un discurso, etc. Para elaborar dicho texto, el estudiante debía recurrir y tener presente -como base teóricauno o varios de los temas vistos en la cátedra de Lingüística general).

Las estrategias de organización de la información propiciaron en los alumnos una reorganización constructiva de la información por aprenderse. Además, el estudiante le encontró sentido a la información aprendida y la utilizó. Ellos usaron estrategias, como: categorías (por ejemplo, la clasificación dada por los estudiantes a sus bancos de preguntas -base de los concursos- de acuerdo con las perspectivas lingüísticas estudiadas en la cátedra (ver actividades 9 y 10); la elaboración de mapas mentales (por ejemplo en las actividades 4 y 7); el uso de estructuras y tipos textuales (por ejemplo, la creación de los guiones para la sustentación de los lingüistas, actividad 5). 
Otras estrategias de aprendizaje empleadas por los estudiantes fueron: a) exposiciones (los estudiantes, expusieron, por ejemplo, aspectos teóricos y biográficos de un lingüista (ver actividad 5); b) actividades guiadas (los estudiantes crearon y aplicaron actividades a sus compañeros, por ejemplo, en la actividad 11); c) discusión y trabajo en equipos cooperativos (trabajos y ejercicios grupales, como en el trabajo grupal donde debían preparar y realizar una miniclase, algunos conceptos operativos (Actividad 2), d) revisión y crítica de textos y ejercicios [...] de los alumnos (en algunas actividades, los estudiantes revisaron y evaluaron los textos de sus compañeros, como en la actividad 10; los estudiantes, además, revisaban sus ejercicios escritos; aquí es de anotar, por ejemplo, el mejoramiento alcanzado, en alguna medida, en cuanto la ortografía); e) elaboración de materiales. En las diversas actividades, los discentes elaboraron y sustentaron carteles; cuadros sinópticos, esquemas; mapas mentales (por ejemplo, en la actividad 3); diapositivas; canciones; libros; bancos de preguntas; ruletas lingüísticas; comerciales televisivos, etc.). Al respecto de los carteles, los esquemas y de los mapas mentales:

Una alumna afirma: la elaboración de esquemas, de material físico como carteles y ciertos dibujos elaborados por mí misma, fue muy bueno porque con las imágenes aprendo y me grabo mejor las cosas y puedo dar a conocer mejor los temas aprendidos." Otra estudiante comenta: el mapa mental es llamativo, podemos mezclar dibujos y palabras; no es aburrido [...] y, además, con el mapa mental (sic), podemos dar, en buena medida, nuestra visión sobre el texto, podemos mostrar nuestro aporte, y usamos lo que nos sobra en la casa, y es muy poco el dinero que invertimos, y aprendemos, divirtiéndonos (Diario de campo).

Los alumnos de la cátedra de linguística, a través de su participación en las 11 actividades, fueron vinculando ideas, conceptos, información nueva sobre lingüística general con información relevante que era, e iba siendo, parte de su estructura cognitiva; esta información relevante, a su vez, funcionaba como punto de "anclaje" a la información nueva por aprender. Esto lo lograron merced el uso de las mencionadas estrategias de elaboración y de organización de la información.

\subsection{El desempeño activo del estudiante en el desarrollo de las 11 actividades}

El alumno participó activamente en el desarrollo de las actividades: él recibió contenidos de lingüística general dados por el maestro; relacionó, permanentemente, esta información nueva con su estructura cognitiva, la procesó activamente; la asimiló y la retuvo. Descubrió un nuevo conocimiento, creó y construyó nuevas ideas. Es así como, a partir de la lectura de los textos dados, y de las ideas y propuestas de los alumnos, en la actividad del tema 3, ellos crearon y presentaron unos interesantes trabajos: el subgrupo 1 creó un video 
sobre "la historia de la linguística, a través de cartas Joseph y Amanda nos cuentan cómo fue apareciendo el lenguaje", y el subgrupo 2, creó y presentó una "Pirinola Lingüística"; el subgrupo 3, presentó algunos personajes de la lingüística quienes dieron, en vivo, una información sobre su vida y sus aportes linguísticos a la lingüística; el subgrupo 4, presenta un relato sobre la "historia de la lingüística", a partir de la creación y presentación de unos títeres; el subgrupo 5 crea y presenta un programa televisivo denominado: "La respuesta es correcta"; el subgrupo 6 crea e interpreta la canción "Eres mi gramática"; el subgrupo 7 realizó un programa televisivo de "entrevistas sobre la lingüística" y el subgrupo 8 elaboró e interpretó una canción donde resume el texto de historia de la lingüística.

A más de esto, el estudiante diferenció y organizó conceptos y proposiciones; incorporó a su estructura cognoscitiva los conceptos presentados; comprobó que su estructura fue impactada, intencionada y sustancialmente, al participar activamente en clase. Al respecto, unos alumnos plantean:

Todos los conceptos aprendidos y todo lo que hicimos en este semestre a mi parecer me hizo (sic) ver las cosas desde otro punto de vista más amplio en el cual puedo ver a las personas como seres más capaces de conseguir lo que se proponen realizar en sus vidas [...] (Encuesta aplicada a los estudiantes) [...] Todas las actividades realizadas en la catedra (sic) de lingüística general, me llevaron a una apropiación de los conceptos y temas tratados, debido a que la presentación de dichos trabajos debíamos indagar sobre los temas [para] presentarlos de manera didáctica, creativa, y no quedarnos [solo] con las ideas, que el profesor nos daba como ejemplo, sino poder sacar nuestras propias ideas nuestras propias propuestas para poder, así, superarnos y comprobar que somos capaces de tener imaginación y aprender $[\ldots]$ para mejorar [...] [Otro alumno opina:] realmente todas las actividades aportaron a mi aprendizaje de los diferentes temas, pues cada una requería un proceso de nuestra parte, donde teníamos en cuenta lo que ya sabemos y se adquiría conocimientos nuevos, nuevas ideas (Encuesta aplicada a los estudiantes).

Así mismo, los alumnos respondieron preguntas orales formuladas por el docente 0 por los compañeros durante el desarrollo de las clases y de las actividades; dieron respuesta a interrogantes escritos, en algunos de los ejercicios propuestos. Además, elaboraron diversas estructuras textuales, como: textos informativos, narrativos, descriptivos y argumentativos. Es así como, por ejemplo:

[En el desarrollo de la actividad 6], en varios grupos, se observa organización, responsabilidad y preparación. Unos "alumnos" formulan respuestas muy interesantes a las preguntas de los maestros, por ejemplo, un "docente" pregunta a los "niños" si saben qué es el Flamenco (la lengua), algunos "alumnos" dicen 
que sí, que es un baile. El profesor inmediatamente, hace la aclaración respectiva. (Diario de campo). En el desarrollo del ejercicio escrito, [de la actividad 4], en términos generales, se observa, en los alumnos, un buen manejo de los aspectos teóricos referentes a las disciplinas y campos de la lingüística. Se observa que ellos distinguen y manejan términos como: diacronía, sincronía, sintaxis, lexicografía, geolingüística, entre otras, y la clasificación propuesta por el autor del texto, respecto de las disciplinas y campos de la lingüística. Algunos estudiantes distinguen claramente los términos de fonología y de fonética, y sus respectivos campos de acción. De otra parte, se aprecian opiniones, en el punto 1, como: "También el estudio del lenguaje nos permite llegar a un grado de comprensión de las características específicas de la inteligencia humana y el desarrollo de su capacidad cognitiva, mejorar los procesos de pensamiento, imaginación y capacidad expresiva"; otros estudiantes afirman: "El lenguaje es el medio para llevar a cabo procesos como ideas, emociones y sentimientos, ya que el lenguaje es el principal instrumento de comunicación" (Diario de campo).

En la actividad 10, los discentes llevaron a cabo un interesante proceso de creación escritural de diversos tipos de textos; como: cartas, cuentos, recetas, descripciones de lingüistas; textos donde presentan y defienden sus ideas, etc. Estos textos tuvieron como base temas vistos en clase de lingüística general, y, por supuesto, su gran dosis de creatividad. Ellos participaron activamente y manifestaron gran entusiasmo durante el proceso de creación del texto y en el momento de la premiación del concurso: "Campeón en Lingüística general" (Diario de campo).

Los alumnos participaron, en forma activa, en el desarrollo de las actividades; en estas, ellos pudieron relacionar los contenidos de la cátedra de lingüística con sus conocimientos; así mismo, pudieron procesar, asimilar y retener esta información; así como, descubrir nuevo conocimiento, construir, plantear y aplicar ideas novedosas. Los estudiantes fueron partícipes y protagonistas en todo el proceso.

\subsection{La función orientadora del docente en el proceso pedagógico}

El maestro orientó -durante la realización de las clases y fuera de estas- a los estudiantes con el fin de ayudarles a aclarar sus dudas; a establecer conexiones entre aspectos que ya manejaban y la teoría que se iba abordando; a mostrarles posibles alternativas por donde podían adelantar sus trabajos. A más de lo anterior, el docente empleó lluvia de ideas, algunas lecturas, unos glosarios, explicaciones y orientaciones para poner en contacto a los estudiantes con las distintas temáticas. Aquí es de citar lo siguiente: 
Un estudiante comenta: me pareció interesante que el profe con los temas, lecturas, bibliografía, con su orientación, con su ayuda, con su colaboración y con los ejercicios y las actividades nos dejara ser parte fundamental, protagonistas del desarrollo de la cátedra de linguística; que no se nos considerara como simples receptores pasivos de la "charla del profesor", a "sentarnos a oír al profe o a leer y luego recitarle unas fotocopias". Me gustó que pudiéramos tener en cuenta nuestras propias ideas; que fuéramos los creadores, propiciadores, constructores y organizadores de muchos de los apartados de las actividades (Diario de campo).

\subsection{Las actividades pedagógicas y su contribución en el logro de un mejor nivel de aprendizaje significativo en el estudiante de la cátedra de Lingüística general}

Las actividades facilitaron la creación de un clima armónico donde el alumno sintiera confianza; pudiera relacionar lo aprendido con lo nuevo por aprender; creara e intercambiara ideas; pudiera elaborar y explicar mediante ejemplos; llevara a la práctica lo aprendido, para que este conocimiento se asimilara, y se lograra, así, un aprendizaje duradero.

Las once actividades permitieron que el estudiante pudiera organizar e incorporar el nuevo conocimiento y, así, aprendiera, de una mejor manera, los contenidos de la cátedra de Lingüística general. Es así como el estudiante realizó una interacción entre lo que ya sabe y las temáticas de la asignatura; elaboró y organizó el contenido; construyó y aprendió el significado de las temáticas y no se limitó a aprender "al pie de la letra" ni a reproducir información; por esto, el alumno, por ejemplo, comprendió e interpretó unas lecturas sobre temáticas de lingüística general; usó categorías; desarrolló y analizó ejercicios tanto individual como grupalmente; preparó y sustentó exposiciones; elaboró mapas mentales, ilustraciones, resúmenes, diversos tipos textuales y videos. Merced a estas actividades, los alumnos aplicaron constructos teóricos analizados, y, así mismo, postularon ideas y planteamientos a nivel individual y grupal.

Las actividades propiciaron que los alumnos realizaran procesos de documentación: consultaron textos impresos y virtuales; así como los glosarios dados por el maestro; desarrollaron los diversos ejercicios y participaron, en forma dinámica, en las distintas actividades planteadas en la cátedra. Así mismo, dichas actividades contribuyeron en la cualificación de otros aspectos, como: la expresión oral frente al público -al afrontar el miedo escénico- y la expresión escrita -al elaborar y presentar los escritos, guiones, trabajos y ejercicios-. Las once actividades aportaron, también, para que los educandos elaboraran y utilizaran material pedagógico, y, a través de este, consiguieran un mejor nivel de apropiación de los temas vistos y, a más de esto, varias de las actividades propiciaron 
que los discentes tuvieran un contacto con su futura labor como docentes de Lenguas extranjeras puesto que -en estas actividades- debían llevar a cabo acciones características de este encomiable oficio. Por último, en cuanto lo expuesto por los alumnos, en la encuesta aplicada, se puede afirmar que, a muchos de ellos, les pareció interesante e importante lo abordado en todos los temas vistos en la cátedra. En relación con esto, son interesantes las palabras de un estudiante:

[Los] temas que vimos en este primer semestre fueron muy interesantes y demasiados (sic) productivos, desde los distintos lingïistas como Chomsky, Saussure hasta Van Dijk [...] todos los temas son interesantes, variados y me sirvieron de una manera enorme y lo más importante es que (sic) todo esto lo aprendimos gracias a las actividades tan emocionantes y divertidas que realizamos (Diario de campo).

\section{Conclusiones}

Las 11 actividades pedagógicas propuestas permitieron que los alumnos lograran una aproximación y apropiación pertinente de unos temas básicos, abordados en la cátedra de Lingüística general. Es así como ellos se apropiaron de: terminología, personajes, temáticas básicas, ambientes y unos postulados de ciertas corrientes (Gramática tradicional; Estructuralismo; Generativismo y Lingüística textual) de la lingüística. Estas actividades, además, facilitaron que, en los educandos, se estableciera una articulación pertinente entre lo que ellos sabían o iban aprendiendo y la nueva información sobre los temas de lingüística; además, se diera en los alumnos una actitud dinámica para acercarse y apropiarse de los temas estudiados. Ellos realizaron procesos de documentación: consultaron textos impresos y virtuales; así como los glosarios dados por el maestro; desarrollaron los diversos ejercicios y participaron, en forma dinámica, en las actividades planteadas en la cátedra. Para lograr lo anterior, los postulados del aprendizaje significativo, empleados en la propuesta pedagógica, fueron un basamento pertinente y útil.

Al considerar -como debe ser-, al educando, eje fundamental, protagonista del desarrollo de la cátedra de lingüística, y no un simple receptor de la "charla del profesor" -o como dijo una estudiante: "sentarnos a oír al profe o a leer y luego recitarle unas fotocopias"-, él se siente reconocido, valorado, con más ánimos y deseos por acercarse, de manera más abierta y dispuesta, a las temáticas por trabajar en la clase; por compartir y adquirir conocimientos, propuestas, concepciones y visiones de mundo: El alumno se motiva y se interesa por aprender. Le encanta que se le permita ser creador, propiciador, constructor y organizador de muchos de los apartados de las actividades. El discente, al ser valorado y considerado como agente en la construcción y reconstrucción de su conocimiento, manifiesta su agrado no solo realizando, con responsabilidad y empeño, 
trabajos muy pertinentes, sino, además, expresando sus agradecimientos al maestro y dedicándole algunos de sus trabajos.

\section{Referencias bibliográficas}

Ausubel, D., Novak J., \& Hanesian, H. (1997). Psicología educativa. México: Trillas. Citado por Martínez de Correa, 2007, p. 169.

Ausubel, D. (1968). Educational Psychology: a cognitive view. New York, Holt, Rinehart and Wiston. Citado por Moreira, Marco Antonio. (1997). Aprendizaje significativo, un concepto subyacente, p. 18. En: Moreira, Marco Antonio, Caballero M. C., y Rodríguez, M.L. (Orgs.). Actas del encuentro nacional sobre aprendizaje significativo. España, pp. 19-44, traducción de Ma. Luz Rodríguez Palmero.

Alcaraz Varó, E., y Martínez Linares, M. A. (2004). Diccionario de Lingüística. España: Ariel.

Ávila, R. (2003). La lengua y los hablantes. México: Trillas.

Bara Soro, P. M. (2001). Estrategias metacognitivas y de aprendizaje: estudio empírico sobre el efecto de aplicación de un programa metacognitivo, y el dominio de las estrategias de aprendizaje en estudiantes E.S.O.B.U.P. y universidad. Memoria para optar el título de doctor. España: Universidad Complutense de Madrid.

Barriga Arceo, F., y Hernández Rojas, G. (1999). Estrategias docentes para un aprendizaje significativo. México: McGraw Hill.

Bernal Leongómez, J. (1982). Tres momentos estelares en Lingüística. Bogotá: Instituto Caro y Cuervo.

Camacho de Báez, B. (2003). Metodología de la investigación. Un camino fácil de recorrer para todos. Colombia: Universidad Pedagógica y Tecnológica de Colombia.

Castillo Durán, N., Jaimes Jaimes, G., y Chaparro Peña, R. 0. (2001). Una aproximación a la investigación cualitativa. Colombia: Universidad Pedagógica y Tecnológica de Colombia.

Castro R., J. V., Correa M., J. I., \& Santiago G., A. W. (1999). Lingüística general y lingüística aplicada. Colombia: coedita.

Cisneros Estupiñán, M., \& Silva Villena, Ó. (2010). La conformación de la ciencia lingüística. Desde la antigüedad hasta las proyecciones del siglo XXI. Colombia: Universidad Tecnológica de Pereira. 
Crystal, D. (1994). Enciclopedia del lenguaje. España: Taurus.

Corredor Tapias, J., y Romero Farfán, C. A. (2009-2012). Materiales de la cátedra de lingüística: estructuralismo, generativismo, textolingüistica y funciones del lenguaje. Tunja: Inédito, 2009-2012.

De Saussure, F. (1974). Curso de Lingüística general. Argentina: Losada.

Hernández Sampieri R., Fernández Collado, C., y Baptista Lucio, P. (2010). Metodología de la investigación. Colombia: McGraw Hill.

Martínez de Correa, H. (2007). Aprendizaje significativo: La psicología educativa aplicada en el salón de clases. En: De Zubiría Samper. Enfoques pedagógicos y didácticas contemporáneas. Colombia: Fundación Internacional de Pedagogía Conceptual, Alberto Merani.

Pozo, J. I. (1990). Estrategias de aprendizaje. En: Coll C., Palacios J. y Marchesi, A. (Eds.). Desarrollo psicológico y educación II. Psicología de la educación. Madrid: Alianza.

PROGRAMA DE LINGÜÍSTICA GENERAL. (2013). Universidad Pedagógica y Tecnológica de Colombia. Escuela de Idiomas. Licenciatura en Lenguas Extranjeras. Tunja.

Rodríguez Palmero, M. L. (org.). (2010). La teoría del aprendizaje significativo en la perspectiva de la psicología cognitiva. España: Octaedro.

Sanjurjo, L. 0. y Vera, M. T. (1994). Aprendizaje significativo y enseñanza en los niveles medio y superior. Argentina: Homo sapiens.

Tobón de Castro, L. (2007). La lingüística del lenguaje. Estudios en torno a los procesos de significar y comunicar. Bogotá: Universidad Pedagógica Nacional. 